\title{
The effect of HIV status on clinical outcomes of surgical sepsis in KwaZulu-Natal Province, South Africa
}

\author{
S Green, ${ }^{1,2}$ BSc Hons, MSc, MB BCh, DA; V Y Kong, ${ }^{2} \mathrm{MSc}, \mathrm{PhD}, \mathrm{MRCS} ; \mathbf{J}$ Odendaal, ${ }^{2} \mathrm{BSc}, \mathrm{MMedSci}$; B Sartorius, ${ }^{3} \mathrm{PhD}$; \\ D L Clarke, ${ }^{2} \mathrm{PhD}$, FCS (SA); P Brysiewicz, ${ }^{4} \mathrm{PhD}$; J L Bruce, ${ }^{2}$ FCS (SA); G L Laing, ${ }^{2}$ PhD, FCS (SA); W Bekker, ${ }^{2}$ FCS (SA) \\ ${ }^{1}$ Department of Anaesthesia, Critical Care and Pain, University of KwaZulu-Natal, Pietermaritzburg, South Africa \\ ${ }^{2}$ Pietermaritzburg Metropolitan Surgical Service, Department of Surgery, University of KwaZulu-Natal, Pietermaritzburg, South Africa \\ ${ }^{3}$ Discipline of Public Health Medicine, School of Nursing and Public Health, University of KwaZulu-Natal, Durban, South Africa \\ ${ }^{4}$ School of Nursing and Public Health, University of KwaZulu-Natal, Durban, South Africa
}

Corresponding author: V Y Kong (victorywkong@yahoo.com)

\begin{abstract}
Background. KwaZulu-Natal Province, South Africa (SA), has long been the epicentre of the HIV epidemic, but the impact of HIV co-infection on the clinical outcomes of emergency surgical patients with sepsis remains largely unknown.

Objective. To review our experience with the management of patients with HIV co-infection and to compare the disease spectrum and outcome with those without HIV infection.

Methods. A retrospective study was undertaken at the Pietermaritzburg Metropolitan Surgical Service (PMSS), SA over a 5-year period from January 2010 to December 2014.

Results. A total of 675 patients with a documented surgical source of sepsis were reviewed. Of these, 332 (49\%) were male, and the mean age was 46 (standard deviation 19) years. HIV status was known in 237 (35\%) patients, 146 (62\%) were HIV-positive and the remaining 91 (38\%) were HIV-negative. Other than tuberculosis of the abdomen being significantly more common in HIV-positive than HIV-negative patients ( $10 \%$ v. $2 \%, p=0.033$ ), there were no differences in the spectrum of diseases between the two groups. There were no significant differences in overall morbidity or mortality. When adjusted for CD4 counts, the mortality in HIV-positive patients with a CD4 count $<200$ cells/ $\mu \mathrm{L}$ was $60 \%(15 / 25)$ and in those with a CD4 count $>200$ cells/ $\mu \mathrm{L}$ it was $2 \%(2 / 101)(p<0.001)$.

Conclusion. The clinical presentation and the spectrum of surgical sepsis in patients with HIV co-infection were not markedly different to those in patients who were not HIV-infected. HIV-infected patients with a CD4 count $<200$ cells/ $\mu \mathrm{L}$ had a significantly higher mortality. Management approaches should not differ based solely on the HIV status of patients with surgical sepsis.
\end{abstract}

S Afr Med J 2017;107(8):702-705. DOI:10.7196/SAMJ.2017.v107i8.12045

The HIV epidemic has existed for more than three decades and the prevalence in sub-Saharan Africa is one of the highest in the world, accounting for $\sim 70 \%$ of the global burden of disease. ${ }^{[1]}$ The estimated overall HIV prevalence rate is $\sim 11 \%$ of the total South African (SA) population. KwaZulu-Natal (KZN) Province in SA is at the epicentre of this pandemic. ${ }^{[2,3]}$ About $25 \%$ of the province's adult population live with the virus, compared with a national average of $18 \% \cdot{ }^{[4]}$ In KZN, there are districts with higher rates of infection, e.g. Amajuba district, where $47 \%$ of women attending antenatal clinics tested positive, while $51 \%$ of women aged 25 - 29 years who participated in a household survey in the rural district of Umkhanyakude were found to be HIVpositive. ${ }^{[5]}$ Surveys in Eshowe and Mbongolwane districts, conducted by Médecins Sans Frontières (MSF), reported that women were the most affected by the disease, with $56 \%$ aged between 30 and 39 years currently living with HIV. ${ }^{[6]}$

The introduction of highly active antiretroviral treatment (HAART) has extended the life expectancy of individuals who are HIV-infected, effectively changing infection with this retrovirus from a lethal condition to a manageable chronic disease. Increasing numbers of HIV-infected patients, therefore, present with medical and surgical conditions similar to those seen in HIV-negative patients. Recent studies have shown that irrespective of the use of HAART, sepsis among HIV-infected patients is increasing, while the incidence of acute respiratory insufficiency and Pneumocystisrelated pneumonia is decreasing. ${ }^{[7-9]}$ In HIV-infected patients, sepsis accounted for $12-31 \%$ of HIV-positive patients' admission to intensive care units (ICUs), and was associated with a worse prognosis. ${ }^{[7-10]}$
Despite the significant prevalence of the disease in KZN, the impact of HIV co-infection on the clinical outcome of surgical patients in our setting remains largely unknown. Over a decade ago, and prior to the national roll-out of the HAART programme, a study by Cacala et al. ${ }^{[2]}$ showed that HIV status does not influence the clinical outcome in general surgical patients. Their study included trauma and non-trauma patients, and did not focus solely on the outcome of HIV-infected patients with surgical sepsis. Since the national HAART programme, there has been no subsequent documentation in the literature on the outcome of HIV infection in surgical patients. More specifically, there has not been any documentation on the outcome of surgical sepsis in HIV-infected patients in KZN.

Surgical sepsis is a broad term that covers a spectrum of conditions where patients have a septic process that requires surgical source control. The current understanding of the impact of sepsis on HIVinfected patients is limited, even though, despite the significant increase in survival and quality of life, HIV/AIDS patients have been systematically excluded from sepsis studies. ${ }^{[7]}$

The study objective was to review and quantify the differences in clinical course and outcome between HIV-positive and HIV-negative patients with primary surgical sepsis in a major university hospital in SA.

\section{Methods}

\section{Clinical setting}

This was a retrospective study undertaken at the Pietermaritzburg Metropolitan Surgical Service (PMSS) based at Grey's and Edendale 
hospitals, Pietermaritzburg, SA. Our regional electronic registry was reviewed - from January 2010 to December 2014. KZN is located along the east coast of the country, with a population of $>11$ million; $50 \%$ of the population live in rural areas. The PMSS provides definitive surgical care to the city of Pietermaritzburg, the capital of KZN Province. It also serves as the referral centre for 19 other rural hospitals in the province, with a total catchment population of $>3$ million. ${ }^{[1]}$

\section{The study}

All adult emergency general surgical patients ( $>15$ years of age), who were admitted by the PMSS, were reviewed. All patients fulfilling the American College of Chest Physicians/Society of Critical Care Medicine Consensus criteria for sepsis, severe sepsis or septic shock, ${ }^{[12]}$ and with a documented surgical source of infection, were reviewed. According to these criteria, sepsis is defined as a complex systemic inflammatory response syndrome (SIRS) to infection; severe sepsis is defined as a systemic inflammatory syndrome in response to infection that is associated with acute organ dysfunction; and septic shock is defined as sepsis with refractory hypotension (systolic blood pressure $<90 \mathrm{mmHg}$ or mean arterial pressure $<70 \mathrm{mmHg}$, despite resuscitation with $30 \mathrm{~mL} / \mathrm{kg}$ of crystalloid). SIRS comprises two or more of the following:

- temperature $>38^{\circ} \mathrm{C}$ or $<36^{\circ} \mathrm{C}$

- pulse $>90$ beats/minute

- respiratory rate $>20$ breaths/minute or $\mathrm{PaCO}_{2}<32 \mathrm{mmHg}$

- white cell count $>12 \times 10^{\%} / \mathrm{L}$ or $>10 \%$ immature band forms.

Only surgical patients with a hospital record with laboratory documentation of HIV status were included. As this was a retrospective study based on a prospectively maintained database, no patients were tested as a part of the study. Routine clinical care information was obtained from the database and patients' medical records.

All patients with incomplete records or without a proven surgical source of sepsis were excluded. Data from the registry included basic demographic information, admission physiological parameters, and diagnosis. Clinical outcomes were described in terms of the need for ICU admission, length of hospital stay, morbidity and mortality. Complications during hospitalisation and not related to the primary reason for surgical treatment, were further grouped by organ systems (e.g. hospital-acquired pneumonia was classified as respiratory complications, acute kidney injury as renal complications, and surgical site infection as wound complications). The surgical pathologies were classified into the following categories: intra-abdominal sepsis, limb sepsis, and soft-tissue sepsis. All patients who were proven to be HIV-positive were compared with those who were known to be HIV-negative. Further subgroup comparisons were made in HIV-positive patients based on their CD4 counts (CD $4<200$ cells $/ \mu \mathrm{L}$ or $>200$ cells $/ \mu \mathrm{L}$ ). A CD 4 count $<200$ cells $/ \mu \mathrm{L}$ corresponds to stage III disease; a count greater than this is stage II or I disease.

\section{Statistical analysis}

Data were processed and analysed using Stata 13.0 (StataCorp., USA). Continuous variables were summarised using means and standard deviations (SDs). If there was evidence of skewing/asymmetrical outliers, the median and interquartile range (IQR) were presented instead. Categorical variables were summarised using frequencies and percentages. Differences in means and ranks (if skewed/nonnormal) of continuous variables by HIV status were assessed using Student's $t$-test and Wilcoxon's rank-sum test (Mann-Whitney $U$-test), respectively. An association between categorical explanatory variables and HIV status was assessed using Pearson's $\chi^{2}$ test or Fisher's exact test if there were $<5$ observations in any cell. A $p$-value $<0.05$ was considered statistically significant.

\section{Ethical approval}

Ethical approval for this study and for maintenance of the registry was endorsed by the Biomedical Research Ethics Committee of the University of KZN (ref. no. BE 207/09 and BCA 221/13).

\section{Results}

\section{Demographic characteristics}

During the 5-year study period, 675 patients with a documented surgical source of sepsis were reviewed. Of these, 332 (49\%) were male and the mean age was 46 (SD 19) years. Of the cohort of 675 patients, the HIV status was known in 237 (35\%). Of these, 146 (62\%) were HIV-positive and 91 (38\%) were HIV-negative. The status of the remaining 438 was unknown and was not considered further. The demographics of the HIV-positive and HIV-negative group are given in Table 1 . There were significantly more female and rural patients, as well as concomitant tuberculosis (TB) among HIV-positive patients compared with those who were HIV-negative.

\section{Clinical presentation and disease spectrum}

The clinical characteristics of the patients are summarised in Table 2. The disease spectrum for both groups is given in Table 3. TB of the abdomen was significantly more common in HIV-positive than HIVnegative patients $(10 \%$ v. $2 \%, p=0.033)$. Of the total 237 patients, 194 (82\%) required operative procedures for source control ( HIV-positive v. HIV-negative patients (78\% (114/147) v. $88 \%(80 / 91), p=0.045)$. Table 4 summarises operative interventions for source control in both groups.

\section{Clinical outcomes}

Table 5 compares the number of patients with morbidities (by organ system) and the length of hospital stay between HIV-positive and HIV-negative patients. Some patients had more than one organ system complication, while others had no complications. There were no significant differences in overall morbidity or mortality between these patients.

\section{Mortality by $\mathrm{CD} 4$ count}

Among the HIV-positive patients with a CD4 count $<200$ cells $/ \mu \mathrm{L}$ or stage III disease, mortality was $60 \%(15 / 25)$, while that in patients with $\mathrm{HIV}$ and a CD 4 count $>200$ cells $/ \mu \mathrm{L}$ (stage II and stage I disease) was $2 \%(2 / 101)$. This was highly statistically significant $(p<0.001)$.

\section{Discussion}

The high prevalence of HIV in KZN results in a significant number of patients presenting with an acute surgical illness together with

Table 1. Demographic characteristics of HIV-positive v. HIVnegative patients

\begin{tabular}{|c|c|c|c|}
\hline Demographics & $\begin{array}{l}\text { HIV-positive } \\
(N=146), n(\%)\end{array}$ & $\begin{array}{l}\text { HIV-negative } \\
(N=91), \boldsymbol{n}(\%)\end{array}$ & $p$-value \\
\hline $\begin{array}{l}\text { Age (years), } \\
\text { mean (SD) }\end{array}$ & $37(11)$ & $40(17)$ & 0.052 \\
\hline Male & $57(39)$ & $50(55)$ & $0.017^{\star}$ \\
\hline Female & $89(61)$ & $41(45)$ & \\
\hline Rural & $79(54)$ & $67(74)$ & $0.003^{*}$ \\
\hline Urban & $67(46)$ & $24(26)$ & \\
\hline Active TB & $35(24)$ & $6(7)$ & $0.001^{*}$ \\
\hline
\end{tabular}


Table 2. Clinical presentations of HIV-positive v. HIV-negative patients

\begin{tabular}{|c|c|c|c|}
\hline & $\begin{array}{l}\text { HIV-positive } \\
(N=146) \\
\end{array}$ & $\begin{array}{l}\text { HIV-negative } \\
(N=91)\end{array}$ & \\
\hline Characteristics & Median (IQR) & Median (IQR) & $p$-value ${ }^{\star}$ \\
\hline Systolic BP (mmHg) & $114(104-127)$ & $118(107-136)$ & 0.083 \\
\hline Diastolic BP (mmHg) & $68(58-80)$ & $71(62-82)$ & 0.299 \\
\hline Mean arterial pressure $(\mathrm{mmHg})$ & $84(74-95)$ & $87(78-96)$ & 0.111 \\
\hline GCS on admission & $15(15-15)$ & $15(15-15)$ & 0.620 \\
\hline Respiratory rate (breaths/min.) & $20(16-24)$ & $20(18-24)$ & 0.682 \\
\hline Heart rate (beats/min.) & $111(97-121)$ & $107(94-120)$ & 0.316 \\
\hline White cell count $\left(10^{9} / \mathrm{L}\right)$ & $16(11-21)$ & $16(12-22)$ & 0.303 \\
\hline
\end{tabular}

Table 3. Source of sepsis for HIV-positive v. HIV-negative patients

\begin{tabular}{llll}
\hline & HIV-positive & HIV-negative & \\
Surgical source of sepsis & $(\boldsymbol{N = 1 4 7 ) , \boldsymbol { n } ( \% )}$ & $(\boldsymbol{N}=\mathbf{9 1}), \boldsymbol{n}(\mathbf{\%})$ & $\boldsymbol{p}$-value \\
\hline Appendicitis & $34(23)$ & $25(27)$ & 0.451 \\
Abdominal tuberculosis & $14(10)$ & $2(2)$ & $0.033^{*}$ \\
Biliary sepsis & $13(9)$ & $6(7)$ & 0.534 \\
Other intra-abdominal sepsis ${ }^{*}$ & $22(15)$ & $13(14)$ & 0.885 \\
Perforated peptic ulcer & $11(7)$ & $7(8)$ & 0.953 \\
Non-diabetic limb sepsis & $10(7)$ & $8(9)$ & 0.573 \\
Necrotising fasciitis & $9(6)$ & $7(8)$ & 0.638 \\
Pelvic inflammatory disease & $7(5)$ & $3(3)$ & 0.745 \\
Diabetic limb sepsis & $6(4)$ & $7(8)$ & 0.234 \\
Head and neck abscess & $5(3)$ & $4(4)$ & 0.735 \\
Peri-anal sepsis & $5(3)$ & $0(0)$ & 0.160 \\
Limb abscess & $4(3)$ & $2(2)$ & 1.000 \\
Intra-abdominal abscess & $4(3)$ & $3(3)$ & 1.000 \\
Trunk abscess & $3(3)$ & $4(4)$ & 0.433 \\
${ }^{*}$ Other intra-abdominal sepsis includes perforation of small or large bowel, infective colitis and bowel ischaemia with intra- \\
abdominal soiling.
\end{tabular}

Table 4. Operative procedures for source control in HIV-positive v. HIV-negative patients

\begin{tabular}{llll}
\hline & $\begin{array}{l}\text { HIV-positive } \\
(\boldsymbol{N = 1 1 4}), \boldsymbol{n}(\%)\end{array}$ & $\begin{array}{l}\text { HIV-negative } \\
(\boldsymbol{N = 8 0}), \boldsymbol{n}(\%)\end{array}$ & $\boldsymbol{p}$-value \\
Operative procedure & $69(61)$ & $39(49)$ & 0.104 \\
\hline Laparotomy & $7(6)$ & $9(11)$ & 0.203 \\
Debridement & $12(11)$ & $13(16)$ & 0.241 \\
Amputation & $2(2)$ & $0(0)$ & 0.513 \\
Laparoscopic cholecystectomy & $13(11)$ & $11(14)$ & 0.625 \\
Incision and drainage & $4(4)$ & $1(1)$ & 0.650 \\
Radiological drainage & $3(3)$ & $3(4)$ & 0.692 \\
ERCP & $3(3)$ & $4(5)$ & 0.450 \\
Appendicectomy & $1(1)$ & $0(0)$ & 1.000 \\
Open cholecystectomy & $114 / 147(78)$ & $80 / 91(88)$ & $0.045^{*}$ \\
Total & &
\end{tabular}

HIV co-infection. ${ }^{[1-3]}$ Patients may present with a complication due to their chronic immunosuppressed state or with an unrelated surgical illness. Immunosuppression results in opportunistic infections such as TB and a number of viral infections. In our study, very few patients presented with specific surgical complications of HIV - the most common HIV-associated cause of surgical sepsis was abdominal TB.

Other than TB of the abdomen being significantly more common in HIV-positive patients, there was no difference in the spectrum of disease. There were no complications of visceral vasculopathy, HIV-related cholangiopathy or colitis. This is consistent with the literature, indicating that TB is the overwhelming opportunistic infection associated with HIV disease in Africa. ${ }^{[13-15]}$ Our study showed no significant differences in overall morbidity or mortality between HIVinfected and HIV-uninfected patients. This is in contrast to the documented poorer outcome of sepsis in HIV-infected patients. ${ }^{[7-10]}$ In these studies, no differentiation is made between patients with surgical sepsis and those without.

Sixty-two percent of our study patients with known results were HIV-positive, which is higher than the reported average prevalence $(25.2 \%)$ of HIV in KZN. ${ }^{[4]}$ This might be due to our study having significantly more females and more rural patients, and may reflect documented regional differences in the prevalence of HIV infection. ${ }^{[5,6]}$

The management of patients with a surgical disease and HIV co-infection remains controversial. Many have suggested that HIV co-infection places surgical patients at risk of major morbidity and have advocated a minimalistic and ultimately fatalistic approach to patients with acute surgical emergencies. This view was first challenged by Bhagwanjee et al. ${ }^{[3]}$ at King Edward VIII Hospital in Durban. In his controversial prospective trial, it was shown that HIV co-infection appeared to offer a protective advantage to patients admitted to the surgical ICU. It was postulated that the immunosuppression inherent in HIV infection dampened down the septic response to critical illness. A decade later, Cacala et al., ${ }^{[2]}$ from Prince Mshiyeni Memorial Hospital in Durban, showed that HIV status does not influence the outcome of general surgical admissions and should not influence surgical management decisions. These authors reported that in their heterogeneous population of HIV-positive surgical patients, CD4 counts were unrelated to outcome. Both these studies were from the era prior to the roll-out of the national HAART programme. In general, CD4 count is regarded as being a proxy 
Table 5. Complications (by organ system) and duration of hospital stay in HIVpositive v. HIV-negative patients

\begin{tabular}{llll}
\hline Complications & $\begin{array}{l}\text { HIV-positive } \\
(\boldsymbol{N = 1 4 6}), \boldsymbol{n}(\mathbf{\%})\end{array}$ & $\begin{array}{l}\text { HIV-negative } \\
(\boldsymbol{N}=\mathbf{9 1}), \boldsymbol{n}(\mathbf{\%})\end{array}$ & $\boldsymbol{p}$-value* \\
\hline Neurological & $0(0)$ & $0(0)$ & - \\
Respiratory & $16(11)$ & $11(12)$ & 0.790 \\
Wound & $16(11)$ & $10(11)$ & 0.994 \\
Renal & $11(8)$ & $3(3)$ & 0.259 \\
Gastrointestinal & $11(8)$ & $3(3)$ & 0.259 \\
Cardiac & $2(1)$ & $1(1)$ & 1.000 \\
Urinary & $0(0)$ & $0(0)$ & - \\
$\begin{array}{l}\text { Length of stay in hospital (days), median (IQR) } \\
\text { Mortality }\end{array}$ & $6(3-11)$ & $6(4-12)$ & 0.669 \\
* Pearson's $\chi^{2}$ test for comparison of categorical variables or Fisher's exact test if $<5$ observations in any cell; Wilcoxon's signed- \\
rank test.
\end{tabular}

marker for immune function. In our study, a significant difference in outcome was noted between HIV patients with a CD4 count $<200$ cells $/ \mu \mathrm{L}$ and those with CD4 counts $>200$ cells/ $\mu \mathrm{L}$. HIV-infected individuals with surgical sepsis and a CD4 count $<200$ cells/ $\mu \mathrm{L}$ are 36 times more likely to die than HIVinfected patients who have a CD4 count $>200$ cells $/ \mu \mathrm{L}$. These findings differ from those of Cacala et al. ${ }^{[2]}$ Our findings were consistent with those in the literature. ${ }^{[16,17]}$ Feng et al ${ }^{[18]}$ used logistic regression to determine risk factors for the development of sepsis in surgical patients with HIV-infection, with and without sepsis. They reported that in HIV-infected patients who required surgery for malignancy or sepsis, those with a low CD4 count and with hypoalbuminaemia before surgery, had a higher probability of developing postoperative sepsis. Further studies are required to define the impact of $\mathrm{CD} 4$ counts on other aspects of clinical outcome in surgical patients with sepsis.

\section{Conclusion}

The clinical presentation and spectrum of surgical sepsis disease in patents with HIV coinfection were not markedly different to those in patients who are not infected with HIV. In patients with a CD4 count $<200$ cells $/ \mu \mathrm{L}$, the mortality was significantly higher.

\section{Acknowledgements. None.}

Author contributions. SG: concept, manuscript drafting, data collection and analysis; VYK: concept and manuscript drafting; JO: data capture and management; BS: statistical advice and analysis; DLC: senior author; PB: data analysis and concepts; JLB: data management and capture; GLL: data capture and database design; and WB: data quality control and concepts.

Funding. None.

Conflicts of interest. None.
1. Bowa K, Kawimbe B, Mugala D, et al. A review of HIV and surgery in Africa. Open AIDS J 2016;10:16-23. https://doi. surgery in Africa. Open AIDS

2. Cacala SR, Mafana E, Thomson SR, Smith A. Prevalence of HIV status and CD4 counts in a surgical cohort: Their relationship to clinical outcome. Ann R Coll Surg Engl 2006;88(1):46-51. to clinical outcome. Ann R Coll Surg Eng

3. https://doi.org/10.1308/003588406X83050 Shas status influence the outcome of patients admitted to a surgical intensive care unit? A prospective double blind study. BM]

4. Statistics South Africa. Mid-year population estimate. https://www. statssa.gov.za/publications/P0302/P03022015 (accessed 15 October

5. Joint United Nations Programme on HIV/AIDS. Sub-Saharan Africa AIDS epidemic update: Regional summary. 2008. http:// data.unaids.org/pub/report/2009/jc1700_epi_update_2009_ en.pdf (accessed 26 July 2017).

6. Médecins Sans Frontières. Bending the curves of the HIV/TB epidemic in KwaZulu-Natal. https://www.msf.org.za//system/tdf/ publications/bending_the_curves.pdf (accessed 16 October 2016).

7. Japiassu AM, Amanciao RT, Mesquita EC, et al. Sepsis is a major determinant of outcome in critically ill HIV/AIDS patients. Crit Care 2010;14(4):R152. https://doi.org/10.1186/cc9221

8. Silva Jr. J, de Sousa dos Santos S. Sepsis in AIDS patients: Clinical, etiological and inflammatory characteristics. J Int AIDS Soc 2013;16(1):17344. https://doi.org/10.7448/IAS.16.1.17344

9. Moreira J. The burden of sepsis in critically ill human immunodeficiency virus-infected patients - a brief review. Braz J Infect Dis 2015;19(1):77-81. https://doi.org/10.1016/j. bjid.2014.05.010

10. Mrus JM, Braun L, Yi MS. Impact of HIV/AIDS on care and outcomes of severe sepsis. Crit Care 2005;9(6):R623-R630. https://doi.org/10.1186/cc3811

11. Laing GL, Bruce JL, Skinner DL, et al. Development, implementation, and evaluation of a hybrid electronic medical record system specifically designed for a developing world surgical service. World J Surg 2014:38(6):1388-1397. https://doi.org/10.1007/s00268-013J Surg 2

12. Bone RC, Balk RA, Cerra FB, et al. Definitions for sepsis and organ failure and guidelines for the use of innovative therapies organ failure and guidelines for the use of

13. Clarke DL, Thomson SR, Bissetty T, Madiba TE, Buccimazza I, Anderson F. A single surgical unit's experience with abdominal Anderson F. A single surgical unit's experience with abdominal
tuberculosis in the HIV/AIDS era. World J Surg 2007;31(5):1088tuber.

14. Robbs IV, Paruk N. Management of HIV vasculopathy - a South Robbs JV, Paruk N. Management of HIV vasculopathy - a South
African experience. Eur J Vasc Endovasc Surg 2010;39(Suppl African experience. Eur I Vasc Endovasc Surg 2010,3

15. Robbs JV. Pathogenesis and pathology of HIV-related largevessel disease. S Afr J Surg 2009;47(2):44-45.

16. Lapadula G, Cozzi-Lepri A, Marchetti G, et al. Risk of clinical progression among patients with immunological nonresponse despite virological suppression after combination antiretroviral treatment. AIDS 2013;27(5):769-779. https://doi.org/10.1097/ QAD.0b013e32835cb747

17. Moody F, Deneve JL, Grant W. CD4 count is predictive of outcome in HIV-positive patients undergoing abdominal operations. Am J Surg 2010;200(6):699-700. https:///doi.org/10.1016/j.amjsurg.2010.07.030

18. Feng $T$, Feng $X$, Jiang $C$, et al. Sepsis risk factors associated with HIV-1 patients undergoing surgery. Emerg Microbes Infect 2015;4:e59. https://doi.org/10.103/emi.2015.59

Accepted 28 March 2017 